\title{
əEstimation of Ice Shelf Melt Rate in the Presence of a Thermohaline Staircase
}

\author{
SAtoshi Kimura, Keith W. Nicholls, AND Emily Venables \\ British Antarctic Survey, Cambridge, United Kingdom
}

(Manuscript received 4 June 2014, in final form 19 September 2014)

\begin{abstract}
Diffusive convection-favorable thermohaline staircases are observed directly beneath George VI Ice Shelf, Antarctica. A thermohaline staircase is one of the most pronounced manifestations of double-diffusive convection. Cooling and freshening of the ocean by melting ice produces cool, freshwater above the warmer, saltier water, the water mass distribution favorable to a type of double-diffusive convection known as diffusive convection. While the vertical distribution of water masses can be susceptible to diffusive convection, none of the observations beneath ice shelves so far have shown signals of this process and its effect on melting ice shelves is uncertain. The melt rate of ice shelves is commonly estimated using a parameterization based on a three-equation model, which assumes a fully developed, unstratified turbulent flow over hydraulically smooth surfaces. These prerequisites are clearly not met in the presence of a thermohaline staircase. The basal melt rate is estimated by applying an existing heat flux parameterization for diffusive convection in conjunction with the measurements of oceanic conditions at one site beneath George VI Ice Shelf. These estimates yield a possible range of melt rates between 0.1 and $1.3 \mathrm{~m} \mathrm{yr}^{-1}$, where the observed melt rate of this site is $\sim 1.4 \mathrm{~m} \mathrm{yr}^{-1}$. Limitations of the formulation and implications of diffusive convection beneath ice shelves are discussed.
\end{abstract}

\section{Introduction}

The majority of grounded ice in Antarctica drains through its peripheral ice shelves, the floating extension of the ice sheet where the most profound changes in ice thickness have been observed (Pritchard et al. 2012; Rignot et al. 2013). Ice shelves vary in thickness from a few tens of meters to as much as $2000 \mathrm{~m}$ and provide an important interface between the continental ice sheets and the surrounding ocean. Changes in the shape and thickness of ice shelves can modulate the flow speed of their tributary glaciers (Dupont and Alley 2005; Rott et al. 2002). Thinning of ice shelves because of unsteady ocean melting can reduce lateral and basal traction at the terminus of outlet glaciers, reducing the restriction on the flow of the grounded ice upstream (Shepherd et al. 2004; Schoof 2007), thereby mediating the ice sheet's

๑ Denotes Open Access content.

Corresponding author address: Satoshi Kimura, British Antarctic Survey, High Cross Madingley Road, Cambridge, CB3 0ET, United Kingdom.

E-mail: skimura04@gmail.com contribution to sea level rise. Direct oceanographic measurements beneath ice shelves are limited by the difficulty in gaining access through the ice shelf itself. The access can be made by drilling an ice shelf with a pressurized hot water drill, and the procedure requires expensive logistics. A few measurements have been made beneath ice shelves that are subject to the intrusion of Circumpolar Deep Water (CDW), which retains its temperature a few degrees above the in situ freezing point: George VI Ice Shelf (Cooper et al. 1988) and Pine Island Glacier (Stanton et al. 2013).

The George VI Ice Shelf occupies George VI Sound, a narrow channel running north-south between the west coast of the Antarctic Peninsula and Alexander Island. In a state of equilibrium, an ice shelf loses mass through basal melting and ice front calving at the same rate as it gains mass through the accumulation of snow and the inflow of ice from tributary glaciers. Bishop and Walton (1981) determined that steady-state melt rate of the George VI Ice Shelf varies with position from 1 to $8 \mathrm{~m} \mathrm{yr}^{-1}$, while Potter et al. (1984) estimated an equilibrium melt rate averaged over the entire ice shelf to be $2 \mathrm{~m} \mathrm{yr}^{-1}$. Corr et al. (2002) used a phase-sensitive radar at one site on the southern part of the ice shelf to measure a melt rate of $2.8 \mathrm{~m} \mathrm{yr}^{-1}$ over a 12-day period in December 2000 . 
Jenkins and Jacobs (2008) derived a melt rate from oceanographic data using tracer conservation equations and assuming that the ocean currents were in geostrophic balance; they found melt rates ranging between 2.3 and $4.9 \mathrm{~m} \mathrm{yr}^{-1}$ in March 1994. The modeling study of Holland et al. (2010) found a local maximum melt rate of $\approx 8 \mathrm{~m} \mathrm{yr}^{-1}$ beneath the southern part of the shelf, with the melt rate decreasing to $1 \mathrm{~m} \mathrm{yr}^{-1}$ toward the thinner ice farther north, which is in good agreement with the observations by Bishop and Walton (1981). These studies reveal that the George VI Ice Shelf is currently losing mass, which correlates well with sustained thinning of ice shelves reported in the western part of Antarctic Peninsula (e.g., Pritchard et al. 2012; Rignot et al. 2013). In the Antarctic Peninsula, mean atmospheric temperature has risen rapidly in the past $50 \mathrm{yr}$ (Comiso 2000; Vaughan et al. 2001), and ice shelves in this region have retreated. For example, the Larsen Ice Shelf (Rott et al. 2002) and Wordie Ice Shelf (Doake and Vaughan 1991) have reacted to this warming by disintegrating. The present George VI Ice Shelf may thus represent an ice shelf that is in the process of disintegrating from the surface (Vaughan and Doake 1996) as well as from rapid basal melting by the intrusion of CDW (Bishop and Walton 1981; Talbot 1988).

The majority of measurements beneath ice shelves have been made in the ice shelf cavities flooded with a cold water mass (temperature near the surface freezing point), for example, the Filchner-Ronne (Nicholls et al. 1991; Nicholls and Jenkins 1993; Nicholls et al. 1997), Fimbul (Orheim et al. 1990; Hattermann et al. 2012), Larsen C (Nicholls et al. 2012), and Ross (Gilmour 1979; Jacobs et al. 1979; Arzeno et al. 2014; Robinson et al. 2014) ice shelves. Robin (1979) argues that thermohaline forcing, rooted in the depth dependence of the freezing point of seawater coupled with the exchange of heat and salt at the ice shelf-ocean interface, generates thermohaline convection within these colder subice shelf cavities. The resulting circulation leads to high melt rates near the grounding line, the point where the ice goes afloat, with freezing possible at lower ice shelf drafts (Hellmer and Olbers 1989; Jenkins 1991). The observations lend support to the idea that the circulation beneath the ice shelf is energized by a combination of the ascending plume of meltwater and tidal forcing, with the subice shelf cavity environments not isolated but sensitive to external climatic conditions.

The ice shelf melt rate from given oceanic conditions, such as temperature, salinity, and water speed, is typically estimated using a parameterization, a set of equation that approximate the fluxes of heat and salt from the ocean to the ice. The parameterization is used in various ocean models with different coordinate formulations, for example, $z$-coordinate (Losch 2008), $\sigma$-coordinate
(Grosfeld et al. 1997; Beckmann et al. 1999; Dinniman et al. 2007), isopycnal-coordinate (Holland and Jenkins 2001; Little et al. 2008), and finite-element (Kimura et al. 2013) ocean models. The most commonly used parameterization is a "three-equation model," which conserves the fluxes of heat and salt within the ice-ocean boundary layer and constrains the temperature of the ice-ocean boundary layer to be at the freezing point (e.g., Holland and Jenkins 1999). The three-equation model expresses oceanic transport of heat and salt as a function of the bulk differences in velocity, heat, and salt across the boundary layer based on results from laboratory experiments reported by Kader and Yaglom (1972). The two assumptions that underpin the existing parameterization are 1) a smooth ice base morphology and 2) a fully developed turbulent flow in the boundary layer.

One of the pronounced manifestations of diffusive convection is a thermohaline staircase, a stack of wellmixed layers separated by sharp interfaces. Diffusive convection in the ocean occurs when temperature and salinity increase with increasing depth in the presence of a gravitationally stable stratification. Diffusive convection is prevalent at high latitudes where the logistics of sampling is demanding. However, diffusive convectionfavorable thermohaline staircases have been observed both in the Arctic Ocean (e.g., Neal et al. 1969; Neshyba et al. 1971; Padman and Dillon 1987; Polyakov et al. 2012) and in the Weddell Sea in Antarctica (e.g., Foster and Carmack 1976; Muench et al. 1990; Robertson et al. 1995). Diffusive convection leads to a set of growing oscillations at the interface between cool, fresh, and warm, salty water (e.g., Turner and Stommel 1964; Marmorino and Caldwell 1976; McDougall 1981; Linden and Shirtcliffe 1978; Fernando 1987). A diffusive convection-favorable staircase can be generated in a laboratory by heating a salinity-stratified fluid from below (e.g., Turner and Stommel 1964; Turner 1968; Marmorino and Caldwell 1976; Fernando 1987, 1989a). These experiments show that the destabilizing buoyancy flux provided by the heating generates convection at the bottom and results in successive convective layers separated by sharp interfaces.

We present observations of a thermohaline staircase beneath the George VI Ice Shelf. We apply a parameterization of heat and salt fluxes formulated from a laboratory experiment of heating a stable salinity gradient from below to predict the melt rate at an ice shelf base in the presence of a diffusive convection-favorable staircase. Our formulation to predict the melt rate assumes the absence of shear (a vertically varying horizontal current). While the melting of ice shelves can produce the vertical distribution of water masses that is susceptible to diffusive 


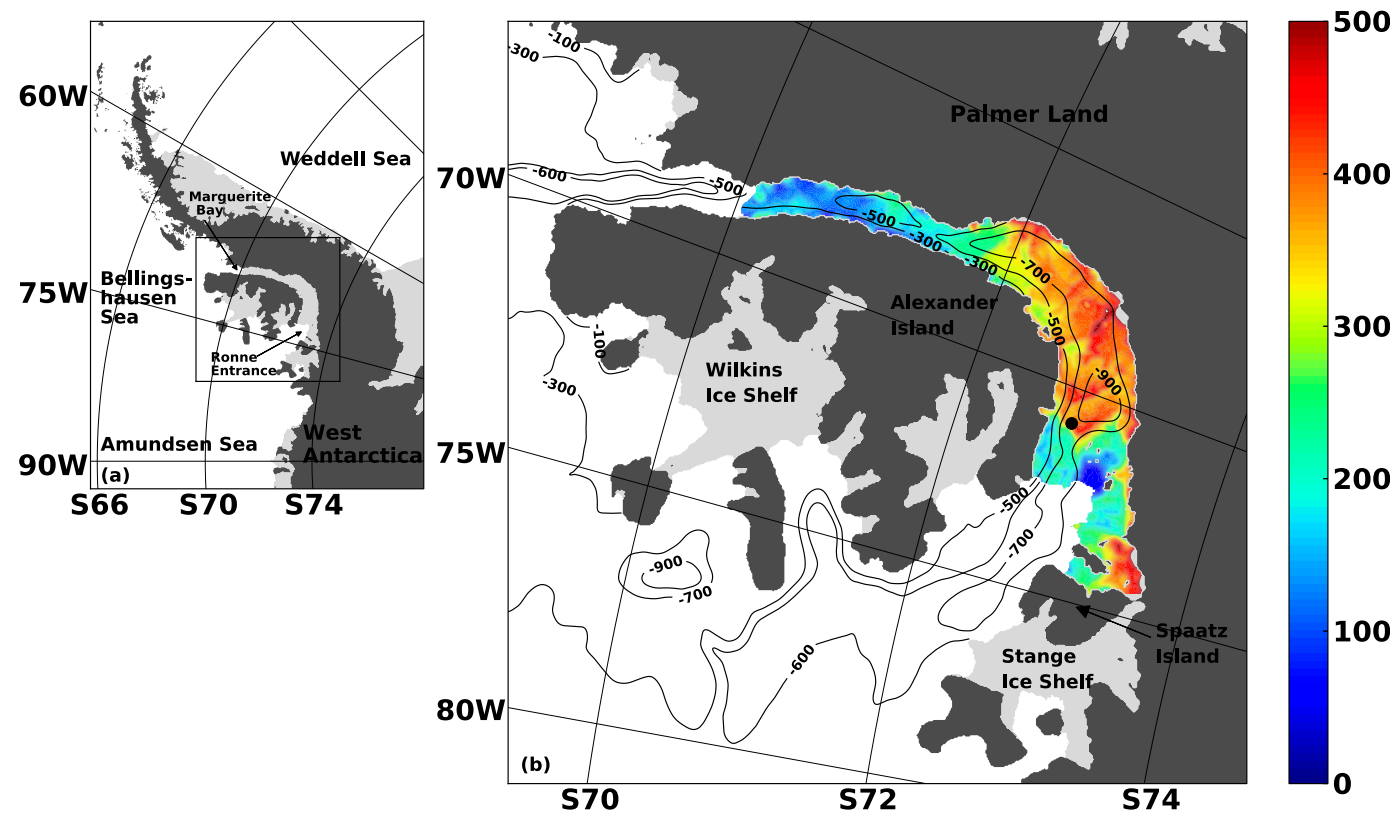

FIG. 1. (a) Map of the Amundsen/Bellingshausen sector of Antarctica showing the area enlarged in Fig. 1 b. (b) Map of the George VI Ice Shelf and surrounding continental shelf. The color scale shows the thickness of the George VI Ice Shelf; contours indicate the bathymetry. The location of two adjacent boreholes $\left(72^{\circ} 49.9^{\prime} \mathrm{S}\right.$ and $\left.70^{\circ} 50.6^{\prime} \mathrm{W}\right)$ is indicated by the black dot.

convection, none of the observations beneath ice shelves have so far detected such signals. Thus, the effect of diffusive convection on melting ice shelves has never before been considered. In the presence of a thermohaline staircase, the assumptions employed in the current framework are not valid to estimate the melt rate of the ice shelf. We present an overview of the diffusive convection-favorable staircase beneath the George VI Ice Shelf in section 2. Section 3 summarizes the threeequation model, the widely used method to predict ice shelf melt rate, based on the assumption of shear-driven turbulence, and presents our formulation, based on the assumption of diffusive convection. The limitations of the formulation and implications of diffusive convection beneath the ice shelf are discussed in section 4. Our conclusions are summarized in section 5 .

\section{Observations}

The George VI Ice Shelf has two ice fronts, one in the north, in Marguerite Bay, and one in the south, in Ronne Entrance (Figs. 1a,b). The maximum ice thickness reaches around $500 \mathrm{~m}$ about $70 \mathrm{~km}$ from Ronne Entrance, where a ridge of thick ice extends across the sound (near $70^{\circ} \mathrm{W}$ ). The vast majority of ice enters the ice shelf from Palmer Land and flows toward Alexander Island (Potter et al. 1984; Humbert 2007). As the ice travels toward the ice fronts, the majority of the continental ice mass from glacier discharge is removed by the high basal melt rate in this region and is replaced by local surface accumulation. In total, the surface accumulation makes up $\sim 20 \%$ of its mass budget (Potter et al. 1984). Both Ronne Entrance and Marguerite Bay are known to be flooded by CDW. It is the intrusion of this water mass beneath the ice shelf that gives rise to rapid basal melting. In the austral summer of 2012, two access holes were drilled at the site $\left(72^{\circ} 49.9^{\prime} \mathrm{S}\right.$ and $\left.70^{\circ} 50.6^{\prime} \mathrm{W}\right)$ a few days apart, allowing for two sets of CTD profiles. In each case, a FastCAT SBE49 CTD and power data interface module (PDIM) interface were lowered down the borehole on a steel frame, recording data at $16 \mathrm{~Hz}$ to a laptop PC. We obtained 12 profiles over a period of $10 \mathrm{~h}$ from the first access hole on 8-9 January 2012 and a further 20 profiles were obtained from the second hole on 12-13 January. In the upper $25 \mathrm{~m}$ of the water column, a low profiling speed of $\sim 0.07 \mathrm{~m} \mathrm{~s}^{-1}$ was used to capture the details of a well-defined staircase. The CTD used pumped sensors that ensured adequate sampling. The depth of the ice base is identified by finding the depth that matches the in situ temperature and freezing temperature, calculated from the salinity and pressure measurements. Salinities are reported using the International Thermodynamic Equation of Seawater2010 (TEOS-10) Absolute Salinity scale (IOC et al. 2010) with the correction factor $\delta S_{\mathrm{A}}=0$, since there are no direct anomaly measurements beneath the ice shelf. At the drill site, the ice thickness and the depth of the 



FIG. 2. Profiles of (a) potential temperature and (b) $T-T_{f}$, where $T_{f}$ is the local freezing temperature. The zero depth indicates the base of the ice shelf.

ocean are approximately 340 and $900 \mathrm{~m}$, giving a water column thickness beneath the ice base of $560 \mathrm{~m}$.

A thermohaline staircase occupies approximately the upper $20 \mathrm{~m}$ of the water column beneath the ice base (Fig. 2a). The temperature at the sea floor is $3.8^{\circ} \mathrm{C}$ above the freezing point local to the ice base (Fig. 2b), consistent with previous observations seaward of the ice fronts (e.g., Bishop and Walton 1981; Talbot 1988). We define a layer as being a portion of the water column with a thickness greater than $0.24 \mathrm{~m}$, having a conductivity gradient much less than the background. An interface is identified as the boundary between adjacent layers. The strength of diffusive convection is measured by the density ratio $R_{\rho}$. The $R_{\rho}$ measures the relative contribution of vertical salinity and temperature gradients to the stability of the water column:

$$
R_{\rho}=\frac{\beta \Delta S}{\alpha \Delta T}
$$

where $\alpha$ and $\beta$ are the thermal expansion and saline contraction coefficients, respectively. The variables $\Delta S$ and $\Delta T$ are salinity and temperature differences across an interface. When both temperature and salinity decrease with depth, salt fingering would be expected for $0<R_{\rho}<1$. However, the observed thermohaline staircases have increasing temperature and salinity with increasing depth (Figs. 3a,b) and $R_{\rho}>1$, which suggests they result from diffusive convection. We restrict our analysis to the diffusive convection-favorable interfaces within the upper $20 \mathrm{~m}$ of the water column. In total, we detected 121 layers from 19 CTD profiles taken between 8 and 13 January. Probability density functions (PDF) of $R_{\rho}$ and $\Delta T$ peak at $2^{\circ}$ and $0.06^{\circ} \mathrm{C}$ with an average of $2.4^{\circ}$ and $0.1^{\circ} \mathrm{C}$, respectively. The properties of the first interface below the ice shelf are anomalous (Fig. 4c), with $R_{\rho}$ and $\Delta T$ tending to be large compared with the remainder and the data points failing to form a cluster.

The thermohaline staircase structure observed here differs in an important respect from that reported by Jacobs et al. (1981) and Neal et al. (1969). Jacobs et al. (1981) observed a staircase structure beside the Erebus Glacier Tongue in Antarctica. Their staircase structure is generated by cooling from the side, analogous to the laboratory experiment of Huppert and Turner (1980). The layering structure beside the Erebus Glacier Tongue occupies the water column from the surface down to a depth of $400 \mathrm{~m}$ (Jacobs et al. 1981). The observed staircase had a statically stable configuration of relatively warm, fresh water overlying cold, salty water, which is not susceptible to diffusive convection but to differential diffusion. Stevens et al. (2014) argues that the layers observed beside the Erebus Glacier Tongue might have formed as a result of shear-driven instability, where the shear is caused by flow over nearby bottom topography. There are no similar topographic features near our drilling sites. Neal et al. (1969) observed diffusive convection-favorable staircases under a drifting ice island in the Arctic, but these staircases were found 220-340 m below the base of the sea ice. In contrast, the diffusive convection-favorable staircase beneath the George VI Ice Shelf is confined to the upper $20 \mathrm{~m}$ of the water column beneath the ice shelf, so, even if the bottom topography existed, it is unlikely to play a role in forming the staircase structure.

The thickness of the layers changes with time, resulting in their coalescing (Fig. 5). The layer thickness may change because of 1) the imbalance in the turbulent kinetic energy between two adjacent layers or 2) the 

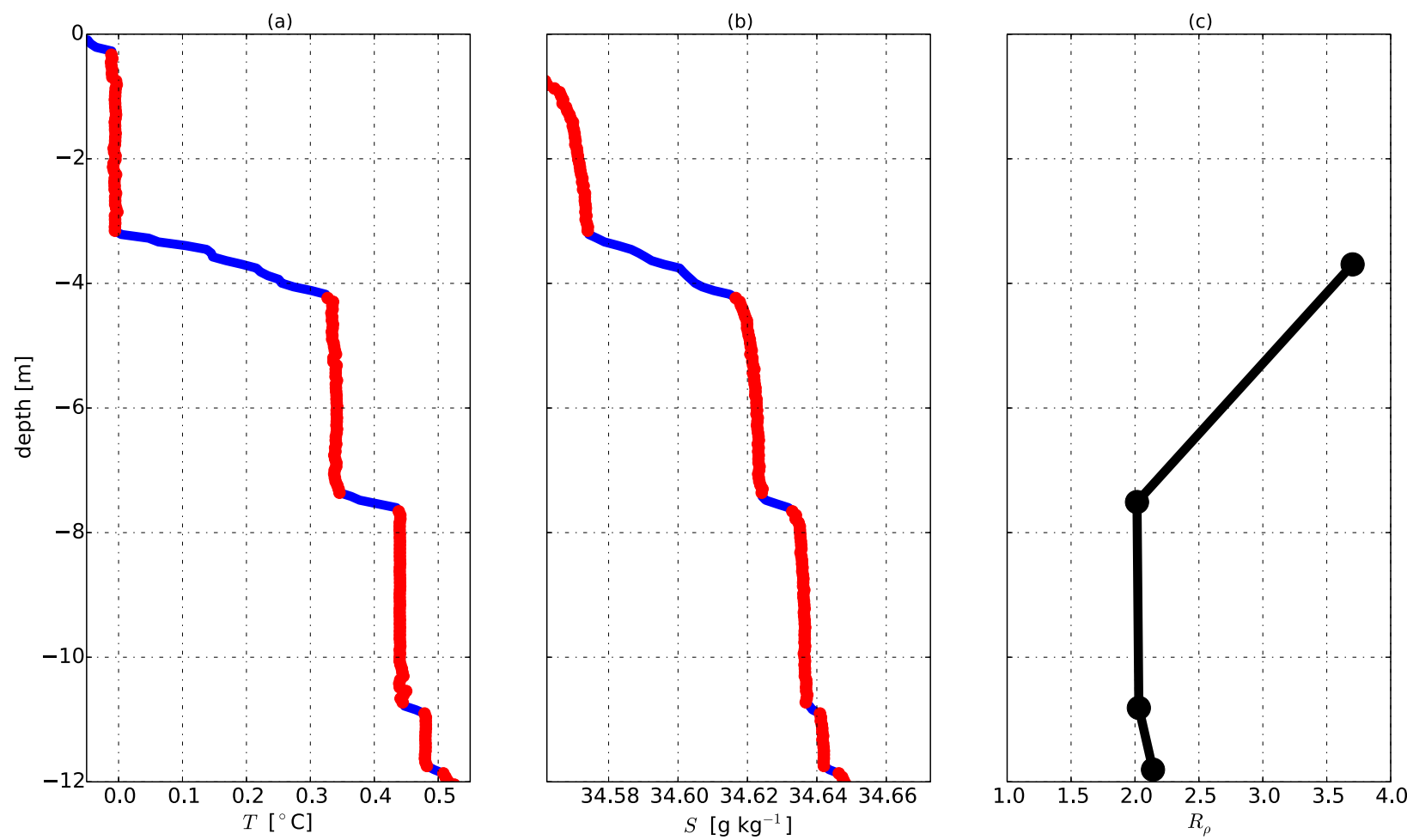

FIG. 3. Profiles of (a) temperature, (b) salinity, and (c) $R_{\rho}$, indicating the result of a layer detection technique based on conductivity gradient. The portions of the water column identified as layers or interfaces are colored red and blue, respectively.

advection of an unchanging layer past the borehole. A thermohaline staircase is known to undergo merging events whereby two adjacent layers coalesce. Radko (2007) proposes two distinct mechanisms: B- and $\mathrm{H}$-merging scenarios. In the B-merging scenario, slightly stronger interfaces strengthen at the expense of weaker interfaces, which gradually erode away, with the position of stronger interfaces remaining stationary. In contrast, in the H-merging scenario slightly thicker layers thicken at the expense of thin layers, which shrink and eventually disappear. Changes in the thickness of layers allow interfaces to drift vertically and eventually to collide with the adjacent interface. Radko (2007) suggests that the dependence of heat and salt fluxes on $\Delta T$ and $\Delta S$ results in the B-merging scenario, whereas the dependence of fluxes on the height of layers can lead to the $\mathrm{H}$-merging scenario. Examples of the B-merging scenarios in field data are presented by Zodiatis and Gasparini (1996) and Radko et al. (2014) who documented the temporal changes in a staircase in the Tyrrhenian Sea and central Canada basin. Numerical simulations of Radko et al. (2014) show that the B-merging scenario is preferred over the H-merging scenario. When the turbulent heat flux within a layer is dominated by convective
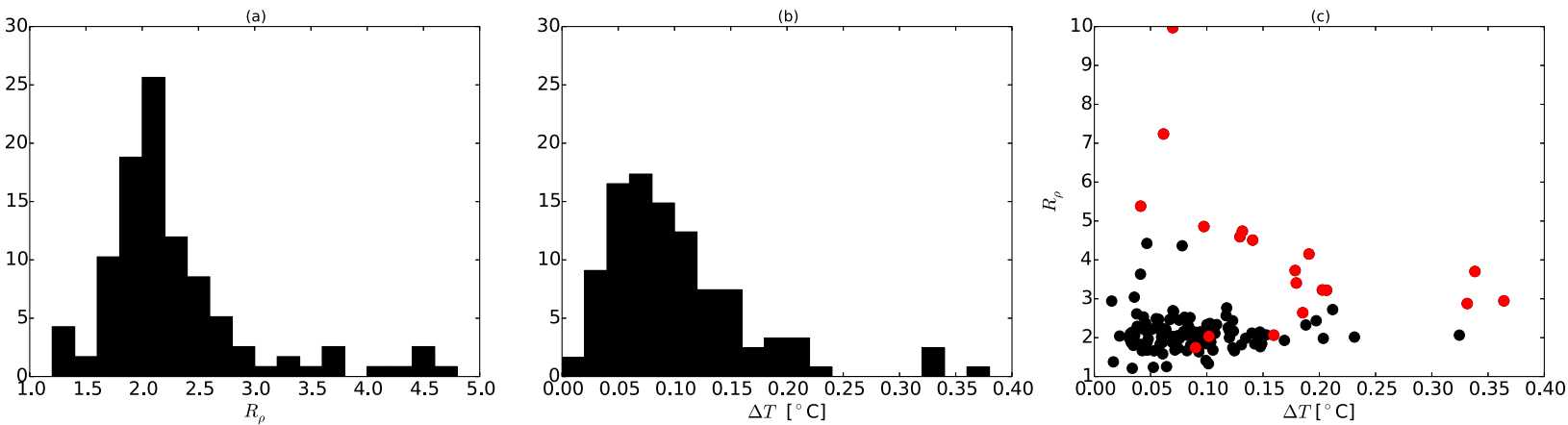

FIG. 4. PDF of (a) $R_{\rho}$ and (b) $\Delta T$. The PDFs are calculated by binning $R_{\rho}$ and $\Delta T$ every $0.2^{\circ}$ and $0.02^{\circ} \mathrm{C}$, respectively. (c) A scatterplot of $\Delta T$ and $R_{\rho}$. Red dots indicate the first layer below the ice shelf. 


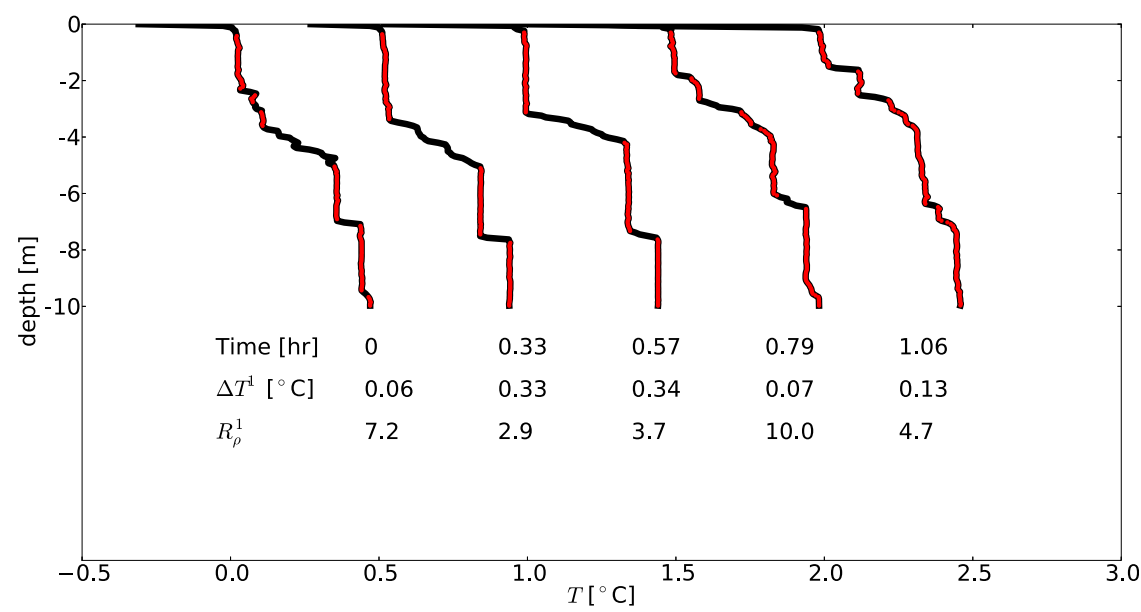

FIG. 5. Evolution of potential temperature profile in the upper $10 \mathrm{~m}$ from the ice shelf between 0645 and $0749 \mathrm{UTC}$ on $9 \mathrm{Jan}$. Each profile is separated by $0.5^{\circ} \mathrm{C}$. The zero depth indicates the base of ice shelf. The red dots on the profiles indicate the layers, whereas the black lines indicate the interfaces. The numbers below the profiles indicates the time in hours with respect to the first profile, the temperature difference between the first and second homogeneous layers beneath the ice shelf $\left(\Delta T^{1}\right)$, and $R_{\rho}$ of the first interface.

elements rising from a thin boundary layer, the flow dynamics are governed by the instabilities within the layer, and the height of the layer becomes unimportant in determining the turbulent heat flux (Turner 1973). This classic argument suggests the preference of the B merger over the $\mathrm{H}$ merger in the oceanic thermohaline staircase, where the layers are sufficiently thick.

In our data, a large temperature step of $\sim 0.3^{\circ} \mathrm{C}$ persists for $15 \mathrm{~min}$, but this step erodes into smaller steps after $30 \mathrm{~min}$ (Fig. 5). Below this step, the $\sim 0.09^{\circ} \mathrm{C}$ interface tends to migrate up and down over the 50-min observation period. Vertical migration of an interface has been observed in a laboratory experiment when the interface is separated by two layers that are subjected to cabbeling (McDougall 1981). Alternatively, the interface migrates when a thermohaline staircase is generated by an external source of buoyancy (e.g., Turner 1968; Marmorino and Caldwell 1976; Fernando 1987). The external buoyancy source causes an imbalance in the turbulent intensities in the adjoining layers, and the interface migrates away from the source (Turner 1968; Marmorino and Caldwell 1976; Fernando 1987). In our case, the ice is a heat sink and acts as a buoyancy sink. One may expect that the first interface below the ice shelf would migrate downward; there are, however, no clear indications of downward migrations in the observations. Our thermohaline staircases appear to be transient, and we are unable to identify the dominant merging scenario from the CTD data.

Exchange of heat and salt between the ice shelf and source water (the water mass that is the source of heat and salt for melting) constrains the temperature and salinity gradients of the water mass beneath an ice shelf in $T-S$ space. Assuming that the turbulent diffusivities of temperature and salinity are equal, any water masses generated by the melting of glacial ice should lie on the meltwater mixing line (Gade 1979). The meltwater mixing line is a straight line in $T-S$ space with a gradient typically lying between $2.4^{\circ}$ and $2.8^{\circ} \mathrm{C} \mathrm{kg} \mathrm{g}^{-1}$, passing through the source water properties (Greisman 1979; Gade 1979). Use of the meltwater mixing line has been successful in deducing source waters from the $T-S$ properties measured beneath ice shelves (e.g., Gade 1979; Nicholls and Jenkins 1993; Hattermann et al. 2012; Nicholls et al. 2012), which lends support to the idea that the flows beneath these ice shelves are fully turbulent. Near the ice base the $T-S$ gradient found in our field observations deviates considerably from the expected value of $2.4-2.8^{\circ} \mathrm{C} \mathrm{kg} \mathrm{g}^{-1}$ (Fig. 6). Our staircase has $R_{\rho}=$ 2 , which corresponds to the $T-S$ slope of 6.8 , and the dotted line in Fig. 6 is parallel with the observed $T-S$ characteristic. This suggests that 1 ) turbulent diffusivities of temperature and salinity are not the same and 2) a role for diffusive convection in modulating the $T-S$ relationship beneath the George VI Ice Shelf.

\section{An estimate of ice shelf melt rate in the presence of a diffusive convection-favorable staircase}

The boundary layer beneath ice shelves can be divided into three distinct but overlapping regions: 1) the viscous sublayer (millimeters to a few centimeters) just below the ice shelf, where molecular processes and surface roughness both influence the mixing; 2) the 


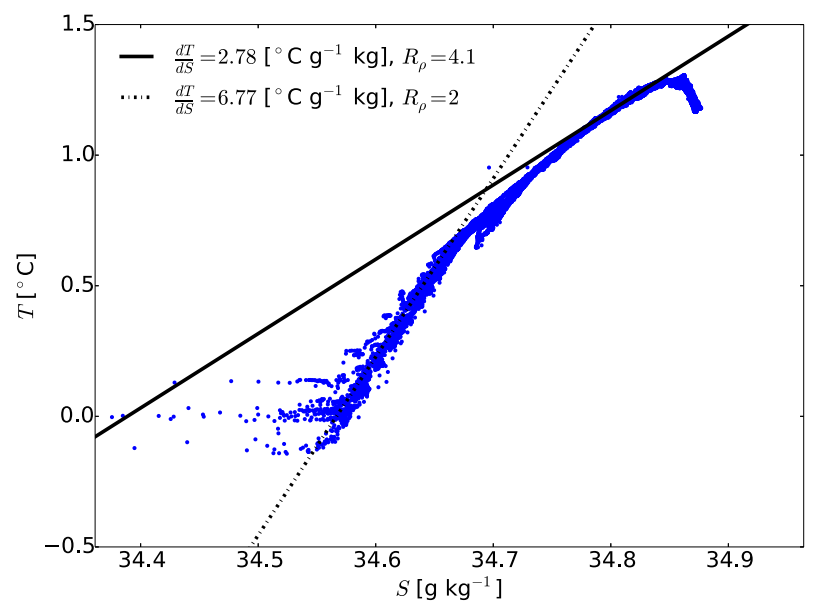

FIG. 6. $T-S$ plot for the borehole data. The solid line indicates the meltwater mixing line with the source water of $T=1.18^{\circ} \mathrm{C}$ and $S=$ $34.80 \mathrm{~g} \mathrm{~kg}^{-1}$. The temperature and salinity relationship, derived from the mean $R_{\rho}=2$, is represented by the dashed line.

inertial sublayer (a few meters), where turbulent mixing is influenced by the proximity and overall roughness of the boundary; and 3) the outer layer (a few tens of meters), where effects of rotation and stratification dominate the mixing (McPhee 2008). The role of the viscous sublayer in regulating the heat and salt fluxes toward the ice base was first recognized by Mellor et al. (1986). Since then, a number of studies have included a different parameterization of the viscous sublayer and turbulent flow in the inertial and outer layers into the prediction of melt rate from given oceanic conditions below the ice, commonly referred to as a three-equation model (e.g., McPhee et al. 1987; Steele et al. 1989; Holland and Jenkins 1999). We begin by briefly summarizing the three-equation model. We then consider heat and salt flux balances between the viscous and inertial sublayers to estimate the melt rate of an ice shelf. We estimate the molecular heat and salt fluxes at the edge of the viscous sublayer by solving the one-dimensional diffusion equations. In our case, the inertial sublayer and outer layer consist of diffusive convection-favorable staircases. We represent the heat and salt fluxes of a diffusive convectionfavorable staircase by applying the parameterization described by Fernando (1987).

\section{a. Three-equation model}

The three-equation model is the most sophisticated parameterization of the ice shelf ocean boundary layer, widely used to predict the melt rate of ice shelves in ocean models (e.g., Hellmer and Olbers 1989; Holland and Jenkins 2001; Losch 2008; Kimura et al. 2013). The model links the local freezing relation and the balance of heat and salt fluxes at the ice shelf-ocean interface. The local freezing relation constrains the temperature $T_{b}$ and salinity $S_{b}$ at the ice shelf-ocean interface:

$$
T_{b}=a S_{b}+b+c P,
$$

where $a=-0.0573^{\circ} \mathrm{C}, b=0.0832^{\circ} \mathrm{C}$, and $c=-7.53 \times$ $10^{-8}{ }^{\circ} \mathrm{CPa}^{-1}$, and $P$ is the local hydrostatic pressure. The balances of heat and salt fluxes between the ice and ocean are

$$
\begin{gathered}
m^{\prime} L+m^{\prime} c_{I}\left(T_{b}-T_{I}\right)=c_{p} \gamma_{T}\left(T_{\infty}-T_{b}\right) \quad \text { and } \\
m^{\prime} S_{b}=\gamma_{S}\left(S_{\infty}-S_{b}\right),
\end{gathered}
$$

where $c_{p}=3974 \mathrm{~J} \mathrm{~kg}^{-1}{ }^{\circ} \mathrm{C}^{-1}$ and $C_{I}=2009 \mathrm{~J} \mathrm{~kg}^{-1}{ }^{\circ} \mathrm{C}^{-1}$ are the specific heat capacities of seawater and ice, respectively. The velocity of the ocean in the direction normal to the ice-ocean interface is represented by $m^{\prime}$ and the melt rate of ice is $m=\rho_{0} m^{\prime} / \rho_{\text {ice }}$, where $\rho_{0}$ and $\rho_{\text {ice }}$ are the density of the ocean and ice, respectively. The variable $L=3.35 \times 10^{5} \mathrm{~J} \mathrm{~kg}^{-1}$ represents the latent heat of ice fusion. The far-field internal temperature of Ronne Ice Shelf, for example, is assumed to be $T_{I}=$ $-25^{\circ} \mathrm{C}$. The terms on the right-hand sides of (3) and (4) are a parameterization of heat and salt transfer toward the ice through the oceanic boundary layer as function of the bulk differences in velocity, heat, and salt across the boundary layer based on Kader and Yaglom (1972). The "far-field" ocean temperature and salinity are represented by $T_{\infty}$ and $S_{\infty}$.

One of the largest uncertainties lies in the exchange coefficients of the heat and salt transfer through the boundary layer $\gamma_{T}$ and $\gamma_{S}$. This is partially because of a lack of measurements beneath ice shelves. Kader and Yaglom (1972) formulated the expressions of $\gamma_{T}$ and $\gamma_{S}$ based on laboratory experiments of a scalar transport in a fully developed turbulent flow over a hydraulically smooth surface:

$$
\begin{aligned}
\gamma_{T} & =\frac{u_{*}}{2.12 \ln \left(u_{*} h / \nu\right)+12.5 \operatorname{Pr}-9} \quad \text { and } \\
\gamma_{S} & =\frac{u_{*}}{2.12 \ln \left(u_{*} h / \nu\right)+12.5 \mathrm{Sc}-9},
\end{aligned}
$$

where Pr and Sc are the molecular Prandtl number (the ratio of viscosity to thermal diffusivity) and Schmidt number (the ratio of viscosity to saline diffusivity), respectively. The variables $h$ and $\nu$ are the thickness of the boundary layer and the kinematic viscosity. The friction velocity $u_{*}$ is defined in terms of kinematic interfacial stress at the ice-ocean interface, which is parameterized as

$$
u_{*}^{2}=C_{d} u_{\infty}^{2},
$$


where $C_{d}$ is a nondimensional drag coefficient. The variable $u_{\infty}$ represents the speed of ocean flow oriented parallel to the ice, which is taken to be the source of turbulence that drives the mixing of heat and salt toward the ice. The above formulation does not consider the modulation of stratification by melting ice. The melting of ice stabilizes the stratification of the boundary layer, and a stable buoyancy flux suppresses the level of turbulence. In contrast, the freezing of ice destabilizes the stratification and leads to convection within the boundary layer. McPhee et al. (1987) incorporated the effect of stratification in the formulation:

$$
\gamma_{T}=\frac{u_{*}}{\Phi+12.5 \operatorname{Pr}-6} \quad \text { and } \quad \gamma_{S}=\frac{u_{*}}{\Phi+12.5 \mathrm{Sc}-6},
$$

where

$$
\Phi=\frac{1}{k} \ln \left(\frac{u_{*} \xi_{N} \eta_{*}^{2}}{f h_{\nu}}\right)+\frac{1}{\xi_{N} \eta_{*}}-\frac{1}{k}
$$

The variables $k$ and $\xi_{N}$ are von Kármán and nondimensional constants. The thickness of the viscous sublayer $h_{\nu}$ is estimated in accordance with Tennekes and Lumley (1972): $h_{\nu}=5 \nu / u_{*}$. The Coriolis parameter is represented by $f$. The influence of the buoyancy flux is apparent in the stability parameter $\eta_{*}$, introduced by McPhee (1981):

$$
\eta_{*}=\left(1+\frac{\eta_{N} u_{*}}{f \mathrm{~L}_{\mathrm{O}} \mathrm{R}_{c}}\right)^{-1 / 2},
$$

where $\mathbf{R}_{c}$ is the critical flux Richardson number (equal to 0.2 ). The variable $\mathrm{L}_{\mathrm{O}}$ is the Monin-Obukhov length, which is the height below the ice shelf at which the buoyancy production of turbulent kinetic energy is equal to that produced by the shearing of the ocean current. McPhee et al. (1987) found that the formulation without the stability parameter $\Phi$ results in unrealistically high melt rates for sea ice in the marginal ice zone of the Greenland Sea. Holland and Jenkins (1999) examined the effect of including $\Phi$ on the calculations of ice shelf melt rate. They found that for thermal driving less than $0.5^{\circ} \mathrm{C}$ and a friction velocity greater than $0.001 \mathrm{~m} \mathrm{~s}^{-1}$ (corresponding to a velocity of about $0.02 \mathrm{~m} \mathrm{~s}^{-1}$ ). Melt rates computed with and without the stability parameter differ by less than $10 \%$, that is, the inclusion of $\Phi$ did not have a large impact on the melt rate, suggesting the precise form of the stability parameter is not critical. While conditions of high positive thermal driving (above $0.5^{\circ} \mathrm{C}$ ) are unlikely to be encountered beneath the Ross and Ice Filchner-Ronne Shelves, ice shelves in the Bellingshausen and Amundsen Seas are subject to the thermal driving of $\sim 2^{\circ} \mathrm{C}$ (Potter et al. 1984; Stanton et al. 2013; Dutrieux et al. 2014).

\section{b. Diffusion of heat and salt within the viscous sublayer}

Melting of ice into seawater cools and freshens the water. When the ice is above the seawater, as in the case of an ice shelf base, the cooling alone destabilizes the stratification of the ambient seawater, while the freshening alone stabilizes the stratification. In this situation, the evolution of the temperature and salinity can be described by one-dimensional diffusion equations (e.g., Martin and Kauffman 1977; Notz et al. 2003):

$$
\frac{\partial T}{\partial t}=\kappa_{T} \frac{\partial^{2} T}{\partial z^{2}} \quad \text { and } \quad \frac{\partial S}{\partial t}=\kappa_{S} \frac{\partial^{2} S}{\partial z^{2}},
$$

where $\kappa_{T}$ and $\kappa_{S}$ are the molecular diffusivities of heat and salt, respectively. Molecular diffusion of salt is two orders of magnitudes lower than that of heat, and therefore the effect of freshening is confined near the ice base, while the effect of cooling can penetrate much deeper. The variable $z$ is the vertical coordinate, increasing upward. At the ice shelf-ocean interface, the temperature $T_{b}$ is at the local freezing point determined by the salinity $S_{b}$ :

$$
T_{b}=a S_{b}+b .
$$

The boundary conditions at the ice shelf-ocean interface are

$$
T[h(t), t]=a S_{b}+b ; \quad S[h(t), t]=S_{b},
$$

where $h(t)$ is the depth of the ice shelf-ocean interface relative to the initial position. The velocity of the ocean in the direction normal to the ice shelf-ocean interface (vertical migration of the interface) is given by $m^{\prime}=\partial h / \partial t$. The melt rate of ice is $m=\rho_{0} m^{\prime} / \rho_{\text {ice }}$. In addition, the heat and salt fluxes from the ocean are in balance with the removal of heat and the addition of freshwater by the ice at $z=h(t)$ :

$$
\begin{aligned}
\operatorname{Lm}^{\prime}(t) & =-c_{p} \kappa_{T} \frac{\partial T}{\partial z} \quad \text { and } \\
S_{b} m^{\prime}(t) & =-\kappa_{S} \frac{\partial S}{\partial z}
\end{aligned}
$$

The diffusion equations in (10), combined with these boundary conditions (12)-(14), admit similarity solutions in which $T(z, t)$ and $S(z, t)$ are functions only of similarity variables $z / h_{T}$ and $z / h_{S}$, where $h_{T}=\sqrt{4 \kappa_{T} t}$ and $h_{S}=\sqrt{4 \kappa_{S} t}$ are the diffusive length scale of heat and salt (e.g., Martin and Kauffman 1977; Notz et al. 2003). The 


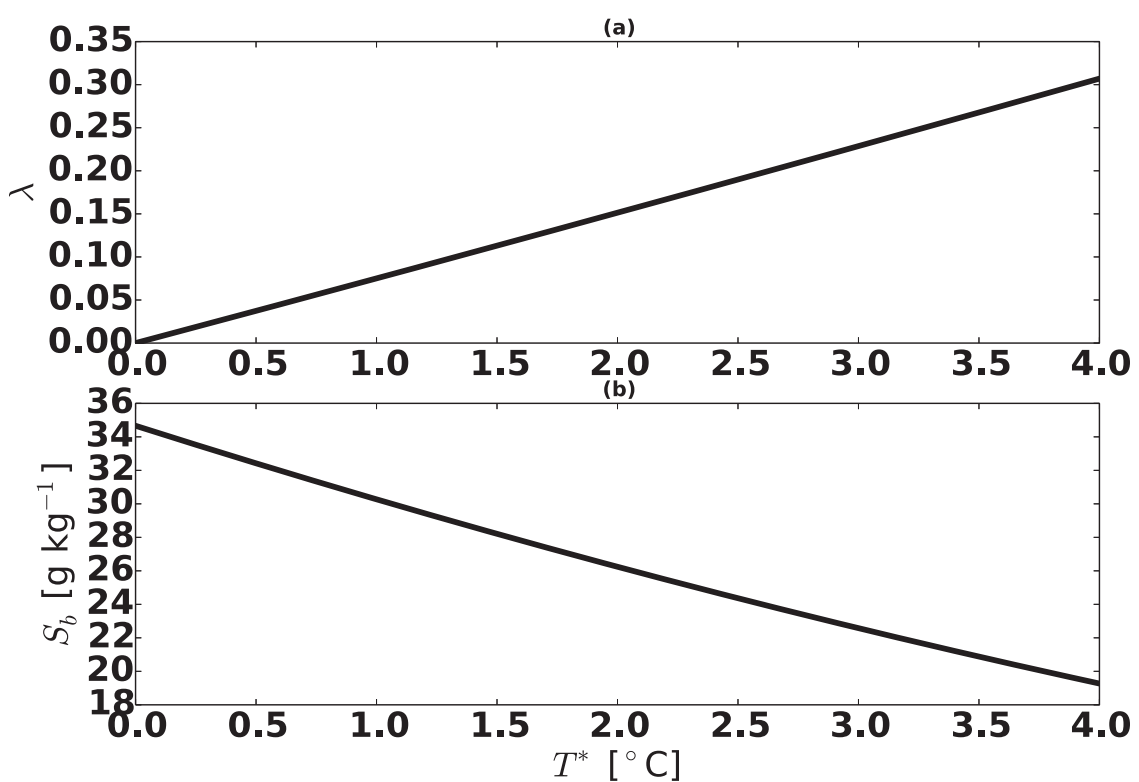

FIG. 7. Dependence of (a) $\lambda$ and (b) $S_{b}$ on $T^{*}$.

solutions for the temperature and salinity field in the ocean in an unbounded domain can then be expressed as $T(z, t)=T_{\infty}+\left(T_{b}-T_{\infty}\right) \frac{\operatorname{erfc}\left(z / h_{T}\right)}{\operatorname{erfc}\left(-\sqrt{\kappa_{S} / \kappa_{T}} \lambda\right)} \quad(z<h) \quad$ and

$S(z, t)=S_{\infty}+\left(S_{b}-S_{\infty}\right) \frac{\operatorname{erfc}\left(z / h_{S}\right)}{\operatorname{erfc}(-\lambda)} \quad(z<h)$,

where

$$
h=2 \lambda \sqrt{\kappa_{S} t} .
$$

The function $\operatorname{erfc}(x)$ is the complementary error function, defined as $\operatorname{erfc}(x)=1-(2 / \sqrt{\pi}) \int_{0}^{x} e^{-s^{2}} d s$. The variables $T_{\infty}$ and $S_{\infty}$ represent the far-field temperature and salinity. The proportionality constant $\lambda, T_{b}$, and $S_{b}$ are determined by substituting the solutions (15)-(17) into the boundary conditions (13) and (14):

$$
\frac{L}{c_{p}}=\frac{T_{b}-T_{\infty}}{F\left(-\sqrt{\frac{\kappa_{S}}{\kappa_{T}}} \lambda\right)} \quad \text { and } \quad S_{b}=\frac{S_{b}-S_{\infty}}{F(-\lambda)},
$$

where

$$
F(x)=\sqrt{\pi} x e^{x^{2}} \operatorname{erfc}(x) .
$$

Equations (12), combined with (18), are solved simultaneously to compute the three unknowns $\lambda, T_{b}$, and $S_{b}$ for given $T_{\infty}$ and $S_{\infty}$. We begin by discussing the behavior of the solutions with respect to the thermal driving $T^{*}$, defined as

$$
T^{*}=T_{\infty}-\left(a S_{\infty}+b\right) .
$$

Increasing $T^{*}$ implies more heat is available to melt the ice, which results in increasing $\lambda$ and decreasing $S_{b}$ (Figs. 7a,b). From the CTD data, the value of $T^{*}$ averaged over the upper $20 \mathrm{~m}$ of the boundary layer is $2.3^{\circ} \mathrm{C}$, with a standard deviation of $0.62^{\circ} \mathrm{C}$. This gives $\lambda \sim O(0.1)$ (Fig. 7a).

The melt rate decays rapidly in time and approaches zero as $t \rightarrow \infty$ (Fig. 8a). A difference of two orders of magnitude between thermal and saline diffusivities generates statically 1) stable and 2) unstable regions beneath the ice (Fig. 8b). Solving the diffusion equations allows us to determine the depth of the boundary between the stable and unstable regions. The vertical derivatives of (15) and (16) are

$$
\begin{aligned}
& \frac{\partial T}{\partial z}=\frac{T_{b}-T_{\infty}}{\operatorname{erfc}\left(-\sqrt{\frac{\kappa_{S}}{\kappa_{T}}} \lambda\right) \sqrt{\pi \kappa_{T} t}} e^{-z^{2} / h_{T}^{2}} \quad \text { and } \\
& \frac{\partial S}{\partial z}=\frac{S_{b}-S_{\infty}}{\operatorname{erfc}(-\lambda) \sqrt{\pi \kappa_{S} t}} e^{-z^{2} / h_{S}^{2}} .
\end{aligned}
$$

We find

$$
h_{R}(t, R)=\sqrt{\frac{4 \kappa_{S} \kappa_{T}}{\kappa_{S}-\kappa_{T}} \ln \left\{R \frac{\alpha L \kappa_{S}}{\beta c_{p} S_{b} \kappa_{T}} e^{\left[\left(\kappa_{S} / \kappa_{T}\right)-1\right] \lambda^{2}}\right\} t},
$$

such that $R=\beta S_{z}\left(-h_{R}, t\right) / \alpha T_{z}\left(-h_{R}, t\right)$. The boundary between the stable and unstable regions is at $z=$ $-h_{R}(t, R=1)$, where the thermal and saline buoyancy gradients compensate each other. In the stable region 

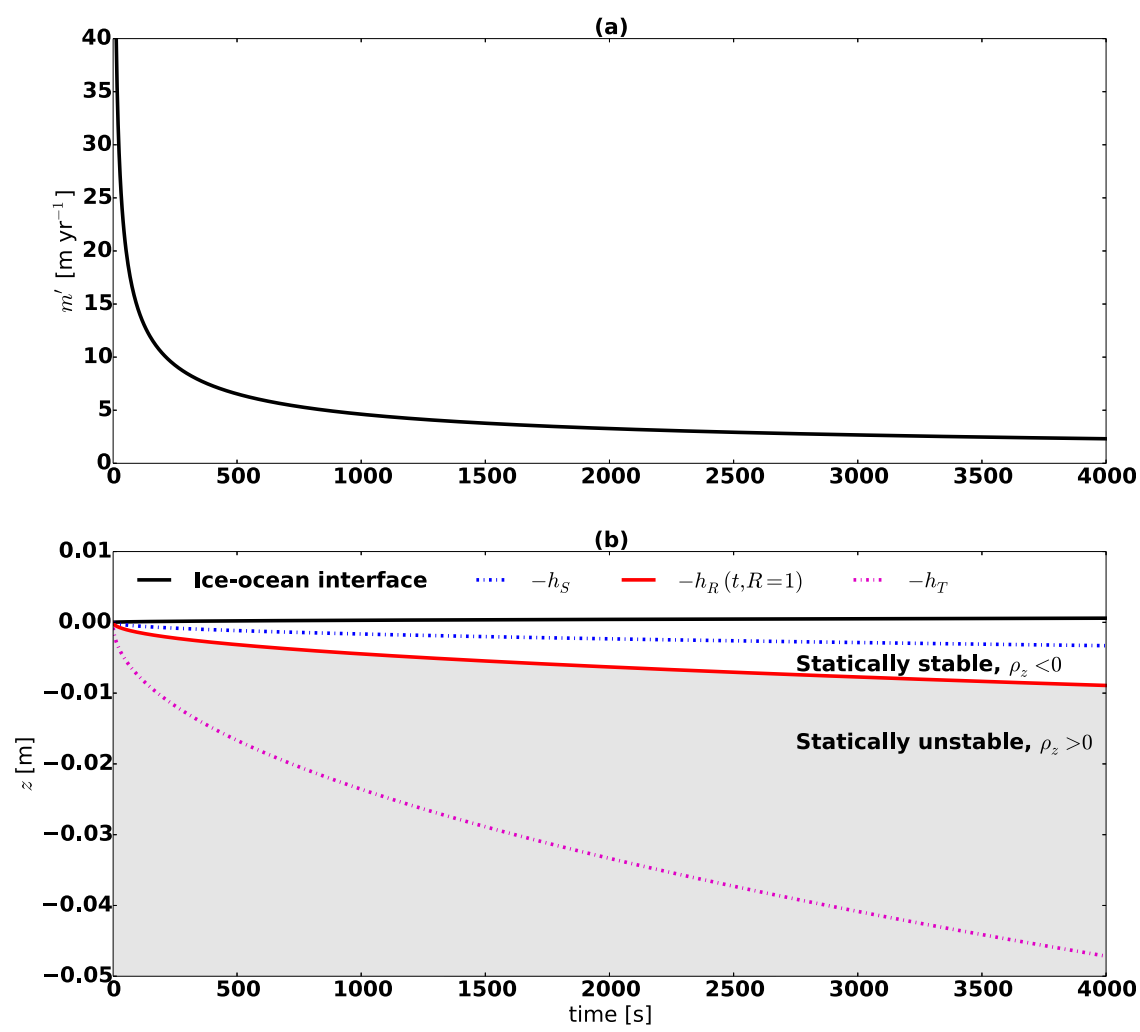

FIG. 8. Evolution of (a) melt rate (b) ice shelf-ocean interface, $h_{S}, h_{R}$, and $h_{T}$. These quantities are calculated by assuming $T_{\infty}=0.45^{\circ} \mathrm{C}$ and $S_{\infty}=34.46 \mathrm{~g} \mathrm{~kg}^{-1}$.

$z>-h_{R}(t, R=1)$, the destabilizing thermal buoyancy gradient is overcompensated by the stabilizing saline buoyancy gradient, resulting in a stably stratified environment. Below the stable region $z<-h_{R}(t, R=1)$, the destabilizing thermal buoyancy gradient overwhelms the stabilizing saline buoyancy gradient, that is, a water parcel near $z=-h_{R}(t, R=1)$ is rapidly cooled and slowly made freshened.

\section{c. Balance of heat and salt fluxes between the viscous and inertial sublayers}

Many laboratory studies have generated a diffusive convection-favorable staircase by heating a salinitystratified fluid from below (e.g., Turner and Stommel 1964; Turner 1968; Marmorino and Caldwell 1976; Fernando 1987, 1989a). Such experiments have found that an initially smooth salinity gradient evolves into well-mixed layers separated by sharp interfaces. The destabilizing thermal buoyancy flux provided by the bottom heating induces the convective motion that forms a well-mixed layer. Once the well-mixed layer reaches a critical thickness, the convective motion is no longer energetic enough to increase it further. The growth of a second layer then begins above the first, and so on. Laboratory experiments of Fernando (1987) show that the growth of the layer occurs by the engulfment of nonturbulent fluid by large-scale eddies near the interface. The eddies inside the well-mixed layer impinge on the interface and engulf the nonturbulent fluid into the well-mixed layer. Fernando (1987) incorporated this process into the estimation of the critical thickness $\delta_{c}$ of the well-mixed layer and rms vertical velocity of fluid motion $w^{*}$ by applying the scaling for convective velocity in turbulent thermal convection formulated by Caughey and Palmer (1979) and Hunt (1984):

$$
\delta_{c}=c_{0} \sqrt{\frac{q_{0}}{N^{3}}}
$$

and

$$
w^{*}=c_{1} \sqrt{\frac{q_{0}}{N}}
$$

where $q_{0}$ and $N$ are the destabilizing thermal buoyancy flux and initial buoyancy frequency, respectively. ${ }^{1}$ The

\footnotetext{
${ }^{1}$ The laboratory experiment of Fernando (1987) heated the salinity-stratified environment, and their formulation uses the initial saline buoyancy frequency instead of $N$.
} 
symbols $c_{0}$ and $c_{1}$ represent constants; $c_{0}=41.5$ and $c_{1}=$ 4.65, determined from laboratory experiments (Fernando 1987). When the well-mixed layer reaches the critical thickness of $\delta_{c}$, the kinetic and potential energy of the overturning eddies are of the same order. At this point, the eddies are not energetic enough to engulf the nonturbulent fluid and instead they tend to flatten at the density interface (Long 1978). Subsequent growth of the well-mixed layer beyond $\delta_{c}$ is much smaller than the initial growth (Fernando 1987).

In the case of melting ice, the destabilizing thermal buoyancy flux is overcompensated by the stabilizing saline buoyancy flux at the ice shelf-ocean interface; however, as the effect of cooling penetrates more quickly than that of freshening, the stratification becomes unstable sufficiently far away from the ice base (Martin and Kauffman 1977). The exact distance in which the stratification becomes unstable is a function of the diffusive length scale of heat and salt. The laboratory experiment of Martin and Kauffman (1977) did not produce a staircase beneath melting ice perhaps as a result of the size and ambient buoyancy gradient used in their experiment. In their experiment, the salinity gradient was very weak in the region where the diffusive convection is thought to occur. $^{2}$ The main difference between Fernando (1987) and this work is in the expression of the destabilizing thermal buoyancy flux $q_{0}$. In the experiment of Fernando (1987), $q_{0}$ is supplied by an array of heating elements, which is a controlled parameter in the experiment. In contrast, we need to solve for the destabilizing thermal buoyancy flux $q_{0}$ by melting ice, so we cast $q_{0}$ in terms of the melt rate of ice:

$$
q_{0}=\frac{g \alpha m^{\prime} L}{c_{p}} .
$$

We assume that the destabilizing thermal buoyancy flux supplied by cooling or heating from above or below the water column has the same effect, and the destabilizing thermal buoyancy flux penetrates much deeper than the stabilizing saline buoyancy flux by the melting of ice. The vertical velocity scale of the overturning circulation within the well-mixed layer below the melting ice can be approximated by substituting (25) into (24):

$$
w^{*}=c_{1} \sqrt{\frac{g \alpha m^{\prime} L}{c_{p} N}} .
$$

\footnotetext{
${ }^{2}$ Martin and Kauffman (1977) noted that diffusive convection can occur in the region between the points $p$ and $q$ on their Figs. 2c and $2 \mathrm{~d}$; however, the salinity at these points is not listed in the paper. It appears that the critical thickness of the well-mixed layer, calculated by (23), becomes larger than the depth of their tank.
}

We assume that the overturning circulation acts to transfer heat and salt toward the ice base and that these fluxes are in balance with the heat and salt fluxes required to melt the ice (Fig. 9). The balance of heat and salt fluxes between the ice and ocean are

$$
\begin{gathered}
-\kappa_{T} \frac{\partial T}{\partial z}=c_{2} w^{*} \Delta T^{1} \text { and } \\
-\kappa_{S} \frac{\partial S}{\partial z}=c_{3} w^{*} \Delta S^{1},
\end{gathered}
$$

where nondimensional coefficients are $c_{2}=4.5 \times 10^{-3}$ and $c_{3}=6.7 \times 10^{-4}$ from the experiments of Fernando (1989a). The terms on the left-hand sides of (27) and (28) are the molecular heat and salt fluxes in the viscous sublayer, which are estimated by (21), the vertical derivatives of (15) and (16). The right-hand side is the estimation of heat and salt fluxes across the first interface below the ice shelf. The variables $\Delta T^{1}$ and $\Delta S^{1}$ represent the temperature and salinity difference between the first and second well-mixed layers below the ice shelf. The two unknowns $z$ and $t$ are solved with (27) and (28) for given $\Delta T^{1}, \Delta S^{1}$, and $N$. Finally, the melt rate is calculated by taking the time derivative of (17):

$$
m=\frac{\rho_{w} \lambda}{\rho_{\text {ice }}} \sqrt{\frac{\kappa_{S}}{t}} .
$$

\section{d. Comparison of model results with observation}

The melt rate of the ice shelf and water flow speed within the upper few meters beneath the ice shelf were measured using upward-looking sonar and current meters mounted on a cable through the borehole. These instruments were placed a few meters from the CTD site. Our measurements show a melt rate and horizontal current speed of around $1.4 \mathrm{~m} \mathrm{yr}^{-1}$ and $0.1 \mathrm{~m} \mathrm{~s}^{-1}$ during the CTD casts. We will use this independent measurement of ice shelf melt rate to assess the results of our melt rate calculation. The widely used three-equation model to estimate the melt rate requires a far-field velocity, temperature, and salinity. The average temperature and salinity $20 \mathrm{~m}$ below the ice shelf are $0.3^{\circ} \mathrm{C}$ and $34.62 \mathrm{~g} \mathrm{~kg}^{-1}$, giving $T_{\infty}=0.3^{\circ} \mathrm{C}$ and $S_{\infty}=34.62 \mathrm{~g} \mathrm{~kg}^{-1}$. Using these observed far-field properties, the three-equation model yields a melt rate of $\sim 50 \mathrm{~m} \mathrm{yr}^{-1}$ (e.g., Holland and Jenkins 1999), which is 30 times larger than the observed melt rate. In addition to $T_{\infty}$ and $S_{\infty}$, our formulation requires $\Delta T^{1}, \Delta S^{1}$, and $N$. The definition of $N$ is an initial buoyancy frequency before the formation of the staircase, which we cannot infer directly from the observations. Fernando (1989b) argues that if each individual 


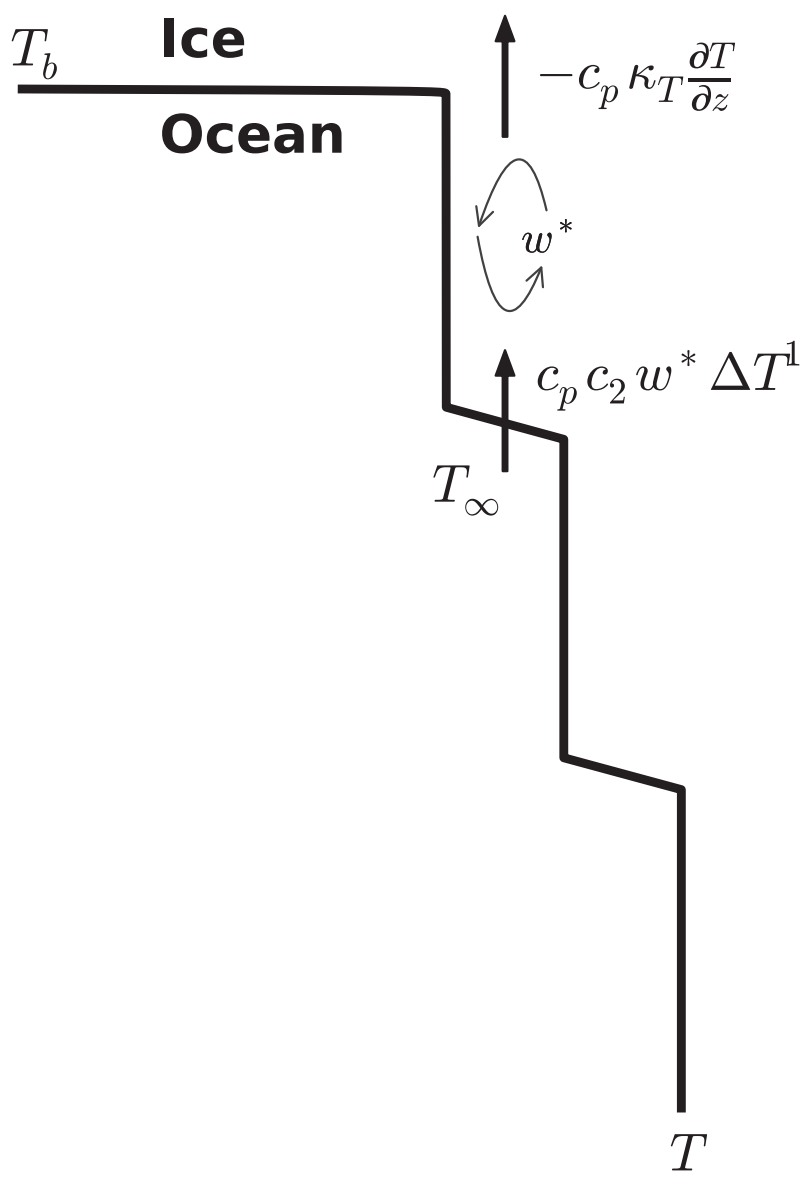

FIG. 9. Schematic representation of the ice shelf-ocean interface and thermohaline staircase.

layer of the staircase forms from an initially smooth salinity profile, then the observed salinity jump across the layer can be used to obtain "smoothed" initial local buoyancy gradient due to salinity:

$$
N^{2} \approx g \beta \frac{\Delta S^{1}}{H},
$$

where $H$ is the thickness of the first well-mixed layer below the ice shelf. We use our layer detection technique described in section 3 to obtain $\Delta T^{1}$ and $N^{2}$. More heat is available to melt the ice with increasing $\Delta T^{1}$, and the overturning eddies in the well-mixed layer become more energetic, which increases the melt rate (Fig. 10). A large portion of our data falls between a melt rate of 0.1 and $0.5 \mathrm{~m} \mathrm{yr}^{-1}$. When the staircase grows to its maximum $\Delta T^{1}$, the calculated melt rate is substantially larger, becoming closer to the observed value of $1.4 \mathrm{~m} \mathrm{yr}^{-1}$.

\section{Discussion}

Previous direct oceanographic measurements beneath ice shelves suggest that the flow in the outer layer is fully

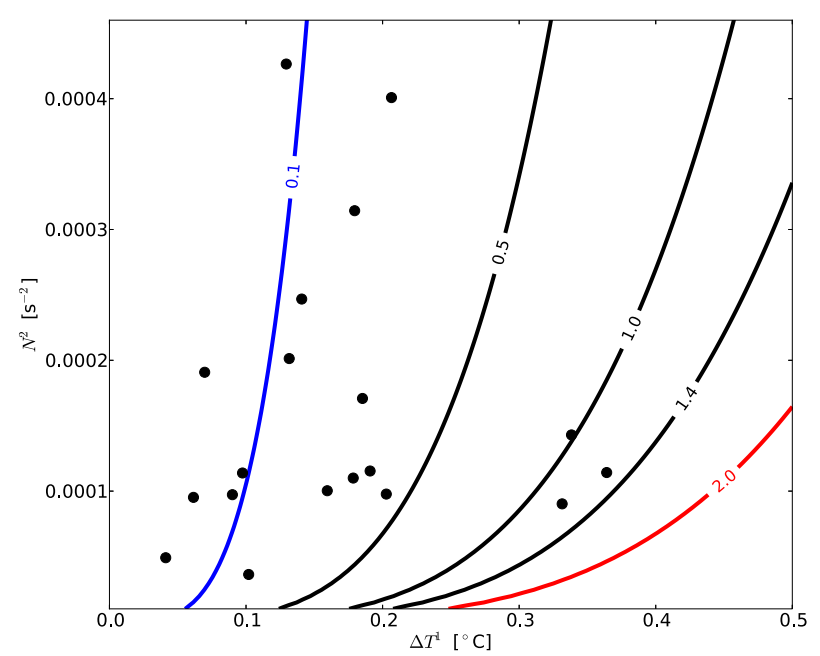

FIG. 10. Melt rate derived from our formulation for different $\Delta T$ and $N^{2}$. Dark dots indicate the observed $\Delta T$ and $N^{2}$ from George VI Ice Shelf. Our measurements show a melt rate of $1.4 \mathrm{~m} \mathrm{yr}^{-1}$ during the CTD casts.

turbulent as a result of the large-scale circulation, modulated by tidal motion (e.g., Gilmour 1979; Jacobs et al. 1979; Nicholls et al. 1991; Nicholls and Jenkins 1993). When the far field is sufficiently energetic, a parameterization based on Kader and Yaglom (1972) is commonly used to represent the heat and salt fluxes within the viscous and inertial sublayers to estimate the melt rate (e.g., Holland and Jenkins 1999; McPhee 2008). This parameterization has been successful in predicting the melt rate of large ice shelves that have a relatively smooth ice base morphology and are surrounded by cold water (near-surface freezing point), such as the Filchner-Ronne Ice Shelf and Larsen C Ice Shelf (e.g., Nicholls and Jenkins 1993; Jenkins et al. 2010; Nicholls et al. 2012). The low melt rate regime decreases the likelihood of a rough base and of strong stratification, while the energetic tidal flows in the sector contribute to maintaining a high level of turbulence (e.g., Makinson and Nicholls 1999). Beneath these ice shelves, Nicholls and Jenkins (1993) conjectured that signatures of diffusive convection had been obliterated by the turbulence associated with the tidal motions and buoyancy-driven ascending plume.

Although the geometric configuration of the George VI Ice Shelf is unique, there are many ice shelves in the eastern Pacific sector of Antarctica that are subject to the intrusion of CDW, which induces high melt rates, complex basal topography, and the possibility of strong stratification. The weak tidal regime in these regions (e.g., Padman et al. 2002) reduces the likelihood of a fully turbulent flow, although with a sloping base, strong melting gives buoyancy-driven flows that might be quite energetic and turbulent. It is unclear if the 
assumptions made in the existing boundary layer parameterization are compatible with these ice shelves. We have applied the existing parameterization of diffusive convection to predict a melt rate of the George VI Ice Shelf, where the upper $20 \mathrm{~m}$ of the water column is occupied by a diffusive convection-favorable thermohaline staircase. In the staircase, the upward molecular diffusion of destabilizing thermal buoyancy flux across the relatively high-gradient interface exceeds stabilizing saline buoyancy flux, resulting in a downward density flux that drives convection in the well-mixed layers. The vertical fluxes in the well-mixed layers are maintained by the convection, while molecular diffusion dominates the transfer of heat and salt at the interfaces. The vertical fluxes of temperature and salinity produce an upgradient density flux rather than the downgradient density flux characteristic of "ordinary" turbulence. As a result, Ruddick and Gargett (2003) argue that diffusive convection is dramatically unlike ordinary turbulence and hence must be considered, and incorporated in models, separately. It is unlikely that diffusive convection can be fully incorporated into the existing ice shelf melt rate parameterizations. Our calculation suggests that diffusive convection can melt the ice up to $1.3 \mathrm{~m} \mathrm{yr}^{-1}$ for the observed oceanic condition beneath the George VI Ice Shelf. However, we do not have measurements beneath other ice shelves to confirm if diffusive convection is a significant process more generally. The vertical distribution of water mass beneath the majority of Antarctic ice shelves is susceptible to diffusive convection (cool, freshwater overlying warm, salty water), but it is likely that the mechanical energy (e.g., tidal force and meltwater outflow) available to obliterate the manifestation of a thermohaline staircase is different. In the presence of weak mechanical energy regime, the thermohaline staircase can survive beneath ice shelves.

Statically stable, density-stratified shear layers are ubiquitous in the ocean. Shear flow beneath an ice shelf cavity can be generated by tides and ascending meltwater plumes. Unlike previously published formulations for estimating melt rate, our formulation ignores the effect of shear beneath an ice shelf and does not consider the possibility of ice formation as a result of in situ supercooling. The density near the freezing point is tightly coupled to salinity, and therefore the formation of ice and the consequential expulsion of salt is likely to result in an unstably stratified environment, leading to pure convection (McPhee 2008). In the presence of sufficiently strong shear, the thermohaline staircase may be obliterated, and the assumptions made in this formulation are no longer valid. Turbulence in the ocean is often governed by a competition between shear, which promotes instability, and statically stable stratification, which acts to stabilize the water column. It is not clear how shear, when combined with diffusive convection, will influence the melt rate. Padman (1994) speculates that shear may act to reduce the stability of the diffusive convection interface, thereby increasing the scalar fluxes, while the shear inhibits scalar fluxes in salt fingering, the other type of double-diffusive convection (Linden 1974; Ruddick 1985; Kunze 1994; Kimura et al. 2011). Laboratory experiments of diffusive convection in the presence of grid-generated turbulence show that the ratio of saline to thermal buoyancy flux can be maintained at a much higher ratio than in the absence of the shear, as a result of an increase in an "entrainment flux" by the mechanical mixing (Crapper 1976). The formulation presented here relies on the flux ratio that prevails in the absence of shear, and some modification will be likely needed to incorporate the effect of shear.

\section{Conclusions}

We observed thermohaline staircases beneath the George VI Ice Shelf. The staircase structure is confined to the upper $20 \mathrm{~m}$ of the water column, which is $500 \mathrm{~m}$ thick. A well-mixed layer occupies the upper few meters of the water column. The observation raises a doubt about the applicability of the widely used three-equation model to predict the melt rate. This motivated us to consider an alternative approach to estimating the melt rate, one that incorporates the effect of diffusive convection. Melting of the ice cools and freshens the ocean below, which both destabilizes and stabilizes the water column, depending on the depth below the ice base. At the ice shelf-ocean interface, the stabilization of buoyancy by the freshening overwhelms the destabilization of buoyancy by the cooling, maintaining the net stable stratification, but the molecular diffusivity of heat is two orders of magnitude larger than salt. As a result, sufficiently far from the ice base $(\sim 1 \mathrm{~cm})$, the cooling of the ocean by the ice generates overturning eddies, thereby creating the staircase in a way that is an inverted analog to the situation of a salt-stratified water column being warmed from below. We have applied the parameterization of heat and salt fluxes formulated and calibrated in laboratory experiments by Fernando (1987). The destabilizing buoyancy flux from the melting of ice dictates the velocity scale of overturning eddies within the well-mixed layer. The eddies impinge on the interface and engulf the nonturbulent fluid into the well-mixed layer, thereby supplying heat to melt the ice. We estimate heat and salt fluxes by the above mechanism beneath the George VI Ice Shelf, and these fluxes are broadly consistent with the observed melt rate of the ice 
shelf. This is the first study to consider the effects of thermohaline staircases beneath a melting ice shelf. More experiments, observations, and numerical simulations are needed to fully understand the role of turbulence and thermohaline staircases on melting ice shelves.

Acknowledgments. Comments from two anonymous reviewers improved the manuscript. The work was supported by the U.K. Natural Environment Research Council under NE/H009205/1.

\section{REFERENCES}

Arzeno, I. B., R. C. Beardsley, R. Limeburner, B. Owens, L. Padman, S. R. Springer, C. L. Stewart, and M. J. M. Williams, 2014: Ocean variability contributing to basal melt rate near the ice front of Ross Ice Shelf, Antarctica. J. Geophys. Res. Oceans, 119, 4214-4233, doi:10.1002/2014JC009792.

Beckmann, A., H. H. Hellmer, and R. Timmermann, 1999: A numerical model of the Weddell Sea: Large-scale circulation and water mass distribution. J. Geophys. Res., 104, 23 375-23392, doi:10.1029/1999JC900194.

Bishop, J., and J. L. W. Walton, 1981: Bottom melting under George VI Ice Shelf, Antarctica. J. Glaciol., 27, 429-447.

Caughey, S. J., and S. G. Palmer, 1979: Some aspects of turbulence structure through the depth of the convective boundary layer. Quart. J. Roy. Meteor. Soc., 105, 811-827, doi:10.1002/ qj. 49710544606 .

Comiso, J. C., 2000: Variability and trends in Antarctic surface temperatures from in situ and satellite infrared measurements. J. Climate, 13, 1674-1696, doi:10.1175/1520-0442(2000)013<1674: VATIAS $>2.0 . \mathrm{CO} ; 2$.

Cooper, S., K. W. Nicholls, E. M. Morris, and M. H. Talbot, 1988: Ice/ocean studies on George VI Ice Shelf 1987/88. British Antarctic Survey Field Rep. R/1987-88/S1.

Corr, H. F. J., A. Jenkins, K. W. Nicholls, and C. S. M. Doake, 2002: Precise measurement of changes in ice-shelf thickness by phase-sensitive radar to determine basal melt rates. Geophys. Res. Lett., 29, doi:10.1029/2001GL014618.

Crapper, P. F., 1976: Fluxes of heat and salt across a diffusive interface in the presence of grid generated turbulence. Int. J. Heat Mass Transfer, 19, 1371-1378, doi:10.1016/ 0017-9310(76)90065-X.

Dinniman, M. S., J. M. Klinck, and W. O. Smith Jr., 2007: Influence of sea ice cover and icebergs on circulation and water mass formation in a numerical circulation model of the Ross Sea, Antarctica. J. Geophys. Res., 112, C11013, doi:10.1029/2006JC004036.

Doake, C. S. M., and D. G. Vaughan, 1991: Rapid disintegration of the Wordie Ice Shelf in response to atmospheric warming. Nature, 350, 328-330, doi:10.1038/350328a0.

Dupont, T. K., and R. B. Alley, 2005: Assessment of the importance of ice-shelf buttressing to ice-sheet flow. Geophys. Res. Lett., 32, 1-4, doi:10.1029/2004GL022024.

Dutrieux, P., and Coauthors, 2014: Strong sensitivity of Pine Island Ice-Shelf melting to climatic variability. Science, 343, 174-178, doi:10.1126/science.1244341.

Fernando, H. J. S., 1987: The formation of layered structure when a stable salinity gradient is heated from below. J. Fluid Mech., 182, 525-541, doi:10.1017/S0022112087002441.
, 1989a: Buoyancy transfer across a diffusive interface. J. Fluid Mech., 209, 1-34, doi:10.1017/S0022112089003010.

- 1989b: Oceanographic implications of laboratory experiments on diffusive interfaces. J. Phys. Oceanogr., 19, 1707-1715, doi:10.1175/1520-0485(1989)019<1707:OIOLEO>2.0.CO;2.

Foster, T., and E. C. Carmack, 1976: Temperature and salinity structure in the Weddell Sea. J. Phys. Oceanogr., 6, 36-44, doi:10.1175/1520-0485(1976)006<0036:TASSIT>2.0.CO;2.

Gade, H., 1979: Melting of ice in sea water: A primitive model with application to the Antarctic Ice Shelf and icebergs. J. Phys. Oceanogr., 9, 189-198, doi:10.1175/1520-0485(1979)009<0189: MOIISW>2.0.CO;2.

Gilmour, A. E., 1979: Ross Ice Shelf sea temperatures. Science, 203, 438-439, doi:10.1126/science.203.4379.438.

Greisman, P., 1979: On upwelling driven by the melt of ice shelves and tidewater glaciers. Deep-Sea Res., 26A, 1051-1065, doi:10.1016/0198-0149(79)90047-5.

Grosfeld, K., R. Gerdes, and J. Determann, 1997: Thermohaline circulation and interaction between ice shelf cavities and the adjacent open ocean. J. Geophys. Res., 102, 15 595-15610, doi:10.1029/97JC00891.

Hattermann, T., O. A. Nøst, J. M. Lilly, and L. H. Smedsrud, 2012: Two years of oceanic observations below the Fimbul Ice Shelf, Antarctica. Geophys. Res. Lett., 39, L12605, doi:10.1029/ 2012GL051012.

Hellmer, H. H., and D. J. Olbers, 1989: A two-dimensional model for the thermohaline circulation under an ice shelf. Antarct. Sci., 1, 325-336, doi:10.1017/S0954102089000490.

Holland, D. M., and A. Jenkins, 1999: Modeling thermodynamic ice-ocean interactions at the base of an ice shelf. $J$. Phys. Oceanogr., 29, 1787-1800, doi:10.1175/1520-0485(1999)029<1787: MTIOIA $>2.0 . \mathrm{CO} ; 2$.

- and - 2001: Adaptation of an isopycnic coordinate ocean model for the study of circulation beneath ice shelves. Mon. Wea. Rev., 129, 1905-1927, doi:10.1175/1520-0493(2001)129<1905: AOAICO $>2.0 . \mathrm{CO} ; 2$.

Holland, P. R., A. Jenkins, and D. M. Holland, 2010: Ice and ocean processes in the Bellingshausen Sea, Antarctica. J. Geophys. Res., 115, C05020, doi:10.1029/2008JC005219.

Humbert, A., 2007: Numerical simulations of the ice flow dynamics of George VI Ice Shelf, Antarctica. J. Glaciol., 53, 659-664, doi:10.3189/002214307784409180.

Hunt, J. C. R., 1984: Turbulence structure in thermal convection and shear-free boundary layers. J. Fluid Mech., 138, 161-184, doi:10.1017/S0022112084000070.

Huppert, H. E., and J. S. Turner, 1980: Ice blocks melting into a salinity gradient. J. Fluid Mech., 100, 367-384, doi:10.1017/ S0022112080001206.

IOC, SCOR, and IAPSO, 2010: The International Thermodynamic Equation of Seawater-2010: Calculation and use of thermodynamic properties. Intergovernmental Oceanographic Commission, Manuals and Guides 56, 220 pp. [Available online at http://www.teos-10.org/pubs/TEOS-10_Manual.pdf.]

Jacobs, S. S., A. L. Gordon, and J. L. Ardai Jr., 1979: Circulation and melting beneath the Ross Ice Shelf. Science, 203, 439-443, doi:10.1126/science.203.4379.439.

- , H. E. Huppert, G. Holdsworth, and D. J. Drewry, 1981: Thermohaline steps induced by melting of the Erebus Glacier Tongue. J. Geophys. Res., 86, 6547-6555, doi:10.1029/ JC086iC07p06547.

Jenkins, A., 1991: A one-dimensional model of ice shelf-ocean interaction. J. Geophys. Res., 96, 20 671-20 677, doi:10.1029/ 91JC01842. 
, and S. Jacobs, 2008: Circulation and melting beneath George VI Ice Shelf, Antarctica. J. Geophys. Res., 113, C04013, doi:10.1029/2007JC004449.

- K. Nicholls, and H. Corr, 2010: Observation and parameterization of ablation at the base of Ronne Ice Shelf, Antarctica. J. Phys. Oceanogr., 40, 2298-2312, doi:10.1175/2010JPO4317.1.

Kader, B., and A. Yaglom, 1972: Heat and mass transfer laws for fully turbulent wall flows. Int. J. Heat Mass Transfer, 15, 23292351, doi:10.1016/0017-9310(72)90131-7.

Kimura, S., W. D. Smyth, and E. Kunze, 2011: Turbulence in a sheared, salt-fingering-favorable environment: Anisotropy and effective diffusivities. J. Phys. Oceanogr., 41, 1144-1159, doi:10.1175/2011JPO4543.1.

, A. S. Candy, P. R. Holland, M. D. Pigott, and A. Jenkins, 2013: Adaptation of an unstructured-mesh, finite-element ocean model to the simulation of ocean circulation beneath ice shelves. Ocean Modell., 67, 39-51, doi:10.1016/ j.ocemod.2013.03.004.

Kunze, E., 1994: A proposed flux constraint for salt fingers in shear. J. Mar. Res., 52, 999-1016, doi:10.1357/ 0022240943076867.

Linden, P. F., 1974: Salt fingers in a steady shear flow. Geophys. Fluid Dyn., 6, 1-27, doi:10.1080/03091927409365785.

—_, and T. G. L. Shirtcliffe, 1978: The diffusive interface in double-diffusive convection. J. Fluid Mech., 87, 417-432, doi:10.1017/S002211207800169X.

Little, C., A. Gnanadesikan, and R. Hallberg, 2008: Large-scale oceanographic constraints on the distribution of melting and freezing under ice shelves. J. Phys. Oceanogr., 38, 2242-2255, doi:10.1175/2008JPO3928.1.

Long, R. R., 1978: A theory of mixing in a stably stratified fluid. J. Fluid Mech., 84, 113-124, doi:10.1017/S0022112078000063.

Losch, M., 2008: Modeling ice shelf cavities in a $\mathrm{z}$ coordinate ocean general circulation model. J. Geophys. Res., 113, C08043, doi:10.1029/2007JC004368.

Makinson, K., and K. W. Nicholls, 1999: Modeling tidal currents beneath Filchner-Ronne Ice Shelf and on the adjacent continental shelf: Their effect on mixing and transport. J. Geophys. Res., 104, 13 449-13 465, doi:10.1029/1999JC900008.

Marmorino, G. O., and D. R. Caldwell, 1976: Heat and salt transport through a diffusive thermohaline interface. Deep-Sea Res. Oceanogr. Abstr., 23, 59-67, doi:10.1016/0011-7471(76)90808-1.

Martin, S., and P. Kauffman, 1977: An experimental and theoretical study of the turbulent laminar convection under a horizontal ice sheet floating on warm salty water. J. Phys. Oceanogr., 7, 272-283, doi:10.1175/1520-0485(1977)007<0272: AEATSO $>2.0 . \mathrm{CO} ; 2$.

McDougall, T. J., 1981: Double-diffusive convection with a nonlinear equation of state: Part II. Laboratory experiments and their interpretation. Prog. Oceanogr., 10, 91-121, doi:10.1016/ 0079-6611(81)90002-1.

McPhee, M. G., 1981: An analytical similarity theory for the planetary boundary layer stabilized surface buoyancy. Bound.-Layer Meteor., 21, 325-339, doi:10.1007/BF00119277.

_ 2008: Air-Ice-Ocean Interaction. Springer, 215 pp.

— - G. A. Maykut, and J. H. Morison, 1987: Dynamics and thermodynamics of the ice/upper ocean system in the marginal ice zone of the Greenland Sea. J. Geophys. Res., 92, 70177031, doi:10.1029/JC092iC07p07017.

Mellor, G. L., M. G. McPhee, and M. Steele, 1986: Ice-seawater turbulent boundary layer interaction with melting or freezing. J. Phys. Oceanogr., 16, 1829-1846, doi:10.1175/ 1520-0485(1986)016<1829:ISTBLI>2.0.CO;2.
Muench, R. D., H. J. S. Fernando, and G. R. Stegen, 1990: Temperature and salinity staircases in the northwestern Weddell Sea. J. Phys. Oceanogr., 20, 295-306, doi:10.1175/ 1520-0485(1990)020<0295:TASSIT>2.0.CO;2.

Neal, V. T., S. Neshyba, and W. Denner, 1969: Thermal stratification in the Arctic Ocean. Science, 166, 373-374, doi:10.1126/ science.166.3903.373.

Neshyba, S., V. T. Neal, and W. Denner, 1971: Temperature and conductivity measurements under ice island T-3. J. Geophys. Res., 76, 8107-8120, doi:10.1029/JC076i033p08107.

Nicholls, K. W., and A. Jenkins, 1993: Temperature and salinity beneath Ronne Ice Shelf, Antarctica. J. Geophys. Res., 98, 22 553-22 568, doi:10.1029/93JC02601.

_ beneath the Ronne Ice Shelf. Nature, 354, 221-223, doi:10.1038/354221a0.

, and M. R. Johnson, 1997: New oceanographic data from beneath Ronne Ice Shelf, Antarctica. Geophys. Res. Lett., 24, 167-170, doi:10.1029/96GL03922.

, - - and E. J. Venables, 2012: Ocean circulation beneath Larsen C Ice Shelf, Antarctica from in situ observations. Geophys. Res. Lett., 39, L19608, doi:10.1029/2012GL053187.

Notz, D., M. G. McPhee, M. G. Worster, G. A. Maykut, K. H. Schlnzen, and H. Eicken, 2003: Impact of underwater-ice evolution on Arctic summer sea ice. J. Geophys. Res., 108, 3223, doi:10.1029/2001JC001173.

Orheim, O., J. O. Hagen, S. Østerhus, and A. C. Saetrang, 1990: Glaciologic and oceanographic studies on Fimbulisen during NARE 1989/90. Filchner Ronne Ice Shelf Programme Rep. 4, 120-131.

Padman, L., 1994: Momentum fluxes through sheared oceanic thermohaline steps. J. Geophys. Res., 99, 22 491-22 499, doi:10.1029/94JC01741.

— Beaufort Sea thermohaline staircase. J. Geophys. Res., 92, $10799-10806$, doi:10.1029/JC092iC10p10799.

- H. A. Fricker, R. Coleman, S. Howard, and L. Erofeeva, 2002: A new tide model for the Antarctic ice shelves and seas. Ann. Glaciol., 34 (1), 247-254, doi:10.3189/172756402781817752.

Polyakov, I. V., A. V. Pnyushkov, R. Rember, V. V. Ivanov, Y. D. Lenn, L. Padman, and E. C. Carmack, 2012: Mooring-based observations of double-diffusive staircases over the Laptev Sea slope. J. Phys. Oceanogr., 42, 95-109, doi:10.1175/2011JPO4606.1.

Potter, J., J. G. Paren, and J. Loynes, 1984: Glaciological and oceanographic calculations of the mass balance and oxygen isotope ratio of a melting ice shelf. J. Glaciol., 30, 161-170.

Pritchard, H., S. Ligtenberg, H. Fricker, D. Vaughan, M. Van den Broeke, and L. Padman, 2012: Antarctic ice-sheet loss driven by basal melting of ice shelves. Nature, 484, 502-505, doi:10.1038/nature10968.

Radko, T., 2007: Mechanics of merging events for a series of layers in a stratified turbulent fluid. J. Fluid Mech., 577, 251-273, doi:10.1017/S0022112007004703.

, J. Flanagan, S. Stellmach, and M. Timmermans, 2014: Doublediffusive recipes. Part II: Layer-merging events. J. Phys. Oceanogr., 44, 1285-1305, doi:10.1175/JPO-D-13-0156.1.

Rignot, E., S. Jacobs, J. Mouginot, and B. Scheuchl, 2013: Ice-shelf melting around Antarctica. Science, 341, 266-270, doi:10.1126/ science.1235798.

Robertson, R., L. Padman, and M. D. Levine, 1995: Fine structure, microstructure, and vertical mixing processes in the upper ocean in the western Weddell Sea. J. Phys. Oceanogr., 100, 18517-18535, doi:10.1029/95JC01742. 
Robin, G., 1979: Formation, flow and disintegration of ice shelves. J. Glaciol., 24, 259-271.

Robinson, N. J., M. J. M. Williams, C. L. Stevens, P. J. Langhorne, and T. G. Haskell, 2014: Evolution of a supercooled ice shelf water plume with an actively growing subice platelet matrix. J. Geophys. Res., 119, 3425-3446, doi:10.1002/2013JC009399.

Rott, H., W. Rack, P. Skvarca, and H. De Angelis, 2002: Northern Larsen Ice Shelf, Antarctica: Further retreat after collapse. Ann. Glaciol., 34, 277-282, doi:10.3189/172756402781817716.

Ruddick, B. R., 1985: Momentum transport in thermohaline staircases. J. Geophys. Res., 90, 895-902, doi:10.1029/JC090iC01p00895.

— troduction. Prog. Oceanogr., 56, 381-393, doi:10.1016/ S0079-6611(03)00024-7.

Schoof, C., 2007: Ice sheet grounding line dynamics: Steady states, stability, and hysteresis. J. Geophys. Res., 112, F03S28, doi:10.1029/2006JF000664.

Shepherd, A., D. Wingham, and E. Rignot, 2004: Warm ocean is eroding West Antarctic Ice Sheet. Geophys. Res. Lett., 31, L23402, doi:10.1029/2004GL021106.

Stanton, T. P., and Coauthors, 2013: Channelized ice melting in the ocean boundary layer beneath Pine Island Glacier, Antarctica. Science, 341, 1236-1239, doi:10.1126/science.1239373.

Steele, M., G. L. Mellor, and M. G. Mcphee, 1989: Role of the molecular sublayer in the melting or freezing of sea ice. J. Phys. Oceanogr., 19,139-147, doi:10.1175/1520-0485(1989)019<0139: ROTMSI $>2.0 . \mathrm{CO} ; 2$.
Stevens, C. L., M. G. McPhee, A. L. Forrest, G. H. Leonard, T. Stanton, and T. G. Haskell, 2014: The influence of an Antarctic Glacier Tongue on near-field ocean circulation and mixing. J. Geophys. Res., 119, 2344-2362, doi:10.1002/ 2013JC009070.

Talbot, M. H., 1988: Oceanic environment of George VI Ice Shelf, Antarctic Peninsula. Ann. Glaciol., 11, 161-164.

Tennekes, H., and J. L. Lumley, 1972: A First Course in Turbulence. MIT Press, 300 pp.

Turner, J., 1968: The behaviour of a stable salinity gradient heated from below. J. Fluid Mech., 33, 183-200, doi:10.1017/ S0022112068002442.

—_, 1973: Buoyancy Effects in Fluids. Cambridge University Press, 367 pp.

- - and H. Stommel, 1964: A new case of convection in the presence of vertical salinity and temperature gradients. Proc. Natl. Acad. Sci. USA, 52, 49-53, doi:10.1073/ pnas.52.1.49.

Vaughan, D. G., and C. Doake, 1996: Recent atmospheric warming and retreat of ice shelves on the Antarctic Peninsula. Nature, 379, 328-331, doi:10.1038/379328a0.

_ , G. J. Marshall, W. M. Connolley, J. C. King, and R. Mulvaney, 2001: Climate change: Devil in the detail. Science, 293, 17771779, doi:10.1126/science.1065116.

Zodiatis, G., and G. P. Gasparini, 1996: Thermohaline staircase formations in the Tyrrhenian Sea. Deep-Sea Res. I, 43, 655678, doi:10.1016/0967-0637(96)00032-5. 